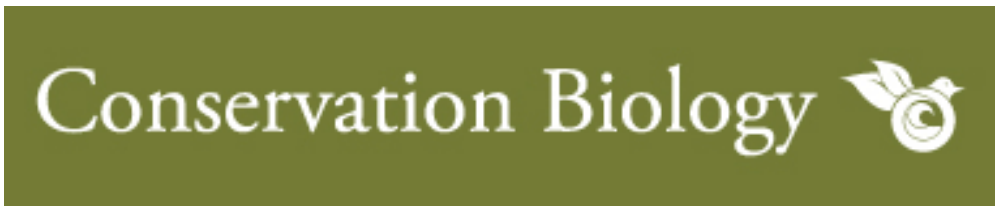

\title{
Effects of the Argentine ant venom on terrestrial amphibians
}

\begin{tabular}{|c|c|}
\hline Journal: & Conservation Biology \\
\hline Manuscript ID & $19-844 . R 2$ \\
\hline Wiley - Manuscript type: & Contributed Paper \\
\hline Keywords: & $\begin{array}{l}\text { amphibian decline, chemical weapons, invasive species, impact } \\
\text { prioritization, Linepithema humile, predator-prey relationships }\end{array}$ \\
\hline Abstract: & $\begin{array}{l}\text { Invasive species have major impacts on biodiversity and are one of the } \\
\text { major causes of amphibian decline and extinction. Unlike other top ant } \\
\text { invaders known to negatively affect larger fauna via chemical defensive } \\
\text { compounds, the Argentine ant (Linepithema humile) does not have a } \\
\text { functional sting; but nonetheless deploys defensive compounds against } \\
\text { competitors and adversaries. We characterised the potential effect of L. } \\
\text { humile's venom on amphibian species, using complementary approaches } \\
\text { (field and laboratory) and comparative analyses (L. humile vs. native ant } \\
\text { species). We estimated levels of ant aggression directed at three native } \\
\text { terrestrial amphibians, the composition and quantities of the toxin used, } \\
\text { and the mechanisms of toxicity in juvenile amphibians. To determine the } \\
\text { potential scope of the threat faced by amphibians, we employed global } \\
\text { databases to estimate the number of terrestrial amphibian species whose } \\
\text { ranges overlapped with those of L. humile, looking at the IUCN Red List } \\
\text { status of those species. We show how juvenile amphibian, co-occurring } \\
\text { spatially and temporally with L. humile, are killed in the ant's trails. } \\
\text { Laboratory tests revealed that, upon contact, the invasive ants rapidly } \\
\text { spray pygidial-gland venom onto the juveniles' permeable skin. Chemical } \\
\text { analyses indicate that iridomyrmecin is the compound responsible: } \\
\text { following absorption, it accumulates in brain, kidney, and liver tissue, } \\
\text { acting at species-dependent doses. Moreover, we estimated that at least } \\
817 \text { terrestrial amphibian species around the world overlap in range with } \\
\text { L. humile, and } 6.2 \% \text { of them are classified as threatened by IUCN. Our } \\
\text { findings highlight the high potential of the venom to negatively affect } \\
\text { amphibian juveniles and provide a basis for exploring the largely } \\
\text { overlooked impacts in this ant in its wide invasive range. }\end{array}$ \\
\hline
\end{tabular}

\section{SCHOLARONE" Manuscripts}




\section{Effects of the Argentine ant venom on terrestrial amphibians}

\section{Abstract}

3 Invasive species have major impacts on biodiversity and are 4 one of the major causes of amphibian decline and extinction.

5 Unlike other top ant invaders known to negatively affect larger fauna via chemical

6 defensive compounds, the Argentine ant ( Linepithema humile) does not have a

7 functional sting; but nonetheless deploys defensive compounds

8 against competitors and adversaries. We characterised the

9 potential effect of $I$. humile's venom on amphibian species, using complementary approaches (field and laboratory) and comparative analyses ( $L$. humile vs. native ant species). We estimated levels of ant aggression directed at three native terrestrial amphibians, the composition and quantities of

14 the toxin used, and the mechanisms of toxicity in juvenile amphibians. To determine the potential scope of the threat

16 faced by amphibians, we employed global databases to estimate the number of terrestrial amphibian species whose ranges overlapped with those of $L$. humile, looking at the IUCN Red List status of those species. We show how juvenile amphibian, co-occurring spatially and temporally with $L$.

21 humile, are killed in the ant's trails. Laboratory tests

22 revealed that, upon contact, the invasive ants rapidly spray

23 pygidial-gland venom onto the juveniles' permeable skin.

24 Chemical analyses indicate that iridomyrmecin is the 
26 in brain, kidney, and liver tissue, acting at species-

27 dependent doses. Moreover, we estimated that at least 817

28 terrestrial amphibian species around the world overlap in

29 range with $L$. humile, and $6.2 \%$ of them are classified as

30 threatened by IUCN. Our findings highlight the high

31 potential of the venom to negatively affect amphibian

32 juveniles and provide a basis for exploring the largely

33 overlooked impacts in this ant in its wide invasive range. 


\section{INTRODUCTION}

36 Amphibians are the most threatened vertebrate taxa worldwide 37 with $41 \%$ of species at risk of extinction

38 (https://www.iucnredlist.org/). Population declines and 39 species extinctions outpace that of mammals and birds since 40 the 1980s (Stuart et al. 2004). Habitat alterations and 41 disease, as well as their synergistic effects with climate 42 change, are key drivers for extinction, (Kiesecker et al. 43 2001; Hof et al. 2011). Overwhelmingly, studies suggest that 44 global amphibian losses are the result of complex interactions among multiple factors acting together on local scales, and in a context-dependent manner (Blaustein \&

47 Kiesecker 2002; Grant et al. 2016). Much of the observed 48 decline is still attributed to "enigmatic decline" (sensu 49 Stuart et al. 2004) and quantifying lesser known threats to 50 amphibians is thus important for developing effective 51 conservation strategies. Invasive species are an additional major causes of

53 amphibian extinctions, through competition, hybridization, 54 bearers of diseases and due to predation (reviewed by Kats \& 55 Ferrer 2003). Invasive ants, three species of which are 56 among the world's worst invaders, have negative consequences 57 for local wildlife, including many amphibian species, due to 58 their opportunistic predation, poisoning, or toxicity 59 (Holway et al. 2002). For example, the red imported fire 
60 ant, Solenopsis invicta, is known for its negative effects

61 on native herpetofauna, birds, and mammals (Allen et al.

62 2004). Its venom is normally injected by stinging and may

63 induce anaphylaxis and, at higher doses, paralysis and even

64 death (Attygalle \& Morgan 1984).

65 Chemical defense has evolved in ants and other social

66 insects to protect their nests. Ants exhibit a plethora of

67 chemicals with a clear evolutionary pathway from

68 proteinaceous pain inducer venom to low molecular organic

69 toxins (Attygalle \& Morgan 1984). In addition to their

70 primary defensive role, they can due to their toxicity also

71 act in an offensive manner for subduing potential prey. They

72 also often act, as such or combined with volatile substances

73 as alarm pheromones, recruiting and eliciting aggression

74 towards foes (Blum 1996).

75

This is well exemplified in one of the top five ant

76 invaders, the Argentine ant L. humile. Although L. humile

77 lacks visible weapons (e.g., a functional sting or large

78 mandibles), it produced substances that include volatile

79 alarm pheromones and defensive allomones (Cavill et al.

80 1976); and a recent study has established that it deploys

81 its defensive compounds against native ants (Welzel et al.

82 2018). Although indirect effects on vertebrates are also

83 known, such as contributing to the decline of the horned

84 lizard (Suarez \& Case 2002) and the spatial shift in habitat 
use of amphibians (Alvarez-Blanco et al. 2017), direct

86 effects, i.e., capacity to subdue vertebrates, which could

87 explain some of the reported indirect effects, have not been 88 demonstrated. Here, we reveal that $L$. humile's use of a toxin can be 90 lethal to juvenile amphibians. We estimated the levels of ant aggression directed at different amphibian species in both the field and the laboratory, and quantified the toxin used. To determine the potential scope of the threat faced by amphibians, we employed global databases to estimate the

95 number of terrestrial amphibian species whose ranges and 96 habitats overlapped with those of the Argentine ant, 97 highlighting particularly those species listed as threatened 98 by the IUCN Red List. Ranges and categories of the Red List are a global standard for conservation studies, ensuring consistency across taxa and regions (Betts et al. in press).

101 Our results present strong evidence that the venom is

102 hazardous to the amphibians tested, and due to the ant's

103 global distribution and extensive overlap with endangered

104 amphibian species, can have serious implications for 105 amphibian conservation. 
109 The Doñana Biological Reserve (RBD, Spain, 3659.491'N, $\left.1106^{\circ} 26.999^{\prime} \mathrm{W}\right)$ hosts both terrestrial amphibians and the

111 invasive Linepithema humile (Díaz-Paniagua et al. 2010;

112 Alvarez-Blanco et al. 2017). We collected individuals of the

113 three most abundant species: natterjack toads (Epidalea

114 calamita), Mediterranean treefrogs (Hyla meridionalis), and

115 western spadefoot toads (Pelobates cultripes) (full methods

116 in Supporting Information). We collected either newly

117 emerged juvenile amphibians near ponds, or tadpoles (that

118 were raised to metamorphosis). Juveniles were housed in

119 groups in terraria, and placed individually in smaller

120 containers during trials. To compare the effects of $L$.

121 humile on amphibians to those inflicted by other ant

122 species, we selected two abundant co-inhabiting native ant

123 species: Aphaenogaster senilis (Myrmecinae) and the closely

124 related Tapinoma cf. nigerrimum (Dolichoderinae) (Arnan et

125 al. 2012). Both ants are generalist feeders including

126 scavenging on animal and plant remains (Arnan et al. 2012),

127 similar to the Argentine ant.

128

129 Spatial and temporal overlap in ant and juvenile amphibian

130 activity at the local scale

131 During the period when newly metamorphosed E. calamita

132 emerged from ponds, we established two plots separated by

$133400 \mathrm{~m}$, which encompassed invaded and uninvaded areas 
134 surrounding ponds. For two consecutive days, we placed baits 135 to record the number and species of ants (a 35-m transect 136 with water-diluted honey and cookie baits placed on 10 pairs 137 of plastic spoons), and counted the number of toadlets (in 138 1-m-wide, 50-m-long transect) throughout the day (at 9:00, $13912: 30,16: 00,19: 30$, and $23: 00)$. To demonstrate the direction of the interaction, i.e.,

141 whether emerging amphibian feed on ants or L. humile

142 predates on them, we inspected, preliminary, relatively permanent

143 L. humile trails near the ponds, revealing dead amphibian in these trails.

144 Subsequently, for four days per year during three years, we counted the number 145 of dead juvenile amphibian found along $40 \mathrm{~m}$ long and $40 \mathrm{~cm}$ 146 wide trails of $L$. humile.

\section{Trail- and foraging-arena exposure experiments}

149 These observations raised two major questions: why juvenile 150 amphibians did not escape from the trail, and, were native ants similarly aggressive towards juveniles? We simulate ant-amphibian encounters experimentally in 153 the field by carefully positioning $P$. cultripes and $H$. 154 meridionalis juveniles $3 \mathrm{~cm}$ away from trails of the three 155 above-mentioned ant species, in perforated cages; either

156 inverted plastic Petri dish $(5.5 \mathrm{~cm}$ in diameter, $1.4 \mathrm{~cm}$ in height, with holes of $4 \mathrm{x} 4 \mathrm{~mm})$, 157 or cages $(8 \times 8.5 \times 3 \mathrm{~cm}$, with a mesh width of $5 \times 5 \mathrm{~mm})$ for the larger A. senilis ant 
158 (Supporting Information). Following initial contact with the 159 ants, the amphibians were kept in place for 2 additional

160 minutes and then released by carefully removing the cage.

161 They were then observed for $10 \mathrm{~min}$ or until they had moved

162 at least $1 \mathrm{~m}$ away from the trail. During these 10 minutes

163 individuals could follow normal activity, either escape or

164 defend themselves from the ants, or get paralyzed; we

165 observed that paralyzed individuals could either recover or

166 die. All individuals were subsequently observed in the

167 laboratory for additional 48 h to monitor the recovery.

168 Individuals were classified as follows: Individuals that

169 remained unaffected, those that escaped or were not

170 paralyzed, were classified as "Alive"; those that recovered

171 after initial paralysis were classified as "Paralyzed"

172 whereas those that died within $48 \mathrm{~h}$ were classified ad

173 "Dead".

174 In laboratory assays, juveniles of either $P$. cultripes,

175 or E. calamita, or H. meridionalis were introduced

176 individually into the foraging arenas of colonies of each of

177 the three above-mentioned ant species, for a maximum of 10

$178 \min (\mathrm{N}=5$ colonies/ant species; see Supporting Information

179 for colony details). We measured the elapsed time to

180 juvenile discovery by the ants and the maximum number of

181 ants found upon it. In cases of apparent harmful effects to

182 the juveniles (the amphibian remained immobile/paralyzed for 
183 one minute or was being dragged off by the ants, risking

184 serious injuryl, trials were stopped earlier. After 48 h of 185 observation, individuals were classified as alive, paralyzed, or dead, as in the previous experiment.

187

188

Histological and chemical differences between $L$. humile and

189

T. Cf. nigerrimum

190

The next step was to determine whether $L$. humile employs a

191 chemical attack. First, we compared the histology of all

192 abdominal exocrine glands of L. humile and T. cf.

193 nigerrimum. Ant gasters were fixed in 2\% glutaraldehyde

194 (buffer: $0.05 \mathrm{M} \mathrm{Na-cacodylate} \mathrm{and} 0.15 \mathrm{M}$ saccharose),

195 postfixed in 2\% osmium tetroxide, and embedded in Araldite.

196 Semithin sections (thickness of 1 um) were created with a

197 Leica EM UC6 ultramicrotome and stained with methylene blue

198 and thionin. These sections were then viewed and

199 photographed with an Olympus BX-51 microscope. We examined

200 the sections meticulously in order to identify all known

201 glands, and look for possible previously undescribed glands.

202

Second, we compared the chemical composition of the

203 pygidial gland of the two species. We dissected the pygidial

204 glands of five freeze-killed ants of each species

205 immediately after death and extracted them in hexane for 24

206 hrs. Compound identification was achieved via gas 
207 chromatography coupled with mass spectrometry (GC-MS), using 208 an HP-5MS capillary column, temperature programmed from $60^{\circ} \mathrm{C}$ 209 (1 min hold) to $320^{\circ} \mathrm{C}$ at a rate of $10^{\circ} \mathrm{C} \cdot \mathrm{min}^{-1}$. For 210 iridomyrmecin quantification extracts of fifty whole ants 211 (10/colony) were used rather than dissected gland to avoid 212 possible spillage during dissection. Decyl-alcohol (99\%) was 213 used as the internal standard. Samples were analyzed by gas 214 chromatography as described above. Calibration curve was 215 established using synthetic iridomyrmecin (Chauhan \& Schmidt 216 2014; Supporting Information).

\section{Iridomyrmecin-exposure experiment}

219 To test iridomyrmecin's toxicity, we applied the synthetic 220 compound to the backs of $P$. cultripes toadlets (isomers 1 221 and 2, in a ratio of 1.5:1). We exposed 10 toadlets to each 222 of three doses of iridomyrmecin dissolved in hexane: $0.1 \mathrm{mg}$, $2231 \mathrm{mg}$, and $5 \mathrm{mg}$ per toadlet and pure hexane as control. Doses 224 were calculated from Choe et al. (2012) estimations, to 225 match naturally occurring concentrations the amphibian would 226 experience in the field. To avoid skin irritation by the 227 hexane solvent, the solutions were applied to cavity slides, 228 allowed the solvent to evaporate, and the slides were rubbed onto the toadlets' backs. After 48 h of observation, individuals were classified as alive (not affected), 
231 paralyzed (recovered from initial paralysis), or dead, as 232 described above.

Dose-response experiment

To assess the number of ants necessary to elicit an effect,

236 we constructed dose-response curves for each ant species and each amphibian species. The number of amphibians was limited to that necessary to obtain adequate dose-response curves

239 (Supporting Information).

241 T. cf. nigerrimum workers that were macerated in a ceramic bowl

242 using $0.2 \mathrm{ml}$ of dechlorinated water. A single dose of the mash was

243 immediately applied to the back of an amphibian. After 10

244 minutes, the individual was gently bathed in dechlorinated water to remove the mash, and

245 we conducted a clinical evaluation based on the presence (or absence)

246 of neurological damage: an individual was considered to be

247 affected by the toxin if an abnormal reaction was displayed

248 in the motor response, the photopupillary reflex or the

249 palpebral reflex (Supporting Information)

251 Physiological effects on juvenile amphibians

252 To elucidate the venom's modus operandi and confirm that the 253 damage was caused by iridomyrmecin, we euthanized the 
254 amphibians used in the above experiment after the clinical

255 evaluation. Half the amphibians were used to quantify

256 iridomyrmecin levels in tissues: animals were dissected to 257 remove their brains, livers, and kidneys, which were then 258 individually extracted in hexane for GC-FID analyses.

259 The other half were used in histological analyses:

260 individuals were fixed in formalin and dissected to obtain

261 their livers and kidneys. Tissue samples were embedded in

262 paraffin wax, sectioned at a thickness of $6 \mu \mathrm{m}$ using a Leica

263 RM 2155 microtome, and mounted on glass slides. Sections

264 were dewaxed through a series of xylene and ethanol washes

265 (from $100 \%$ solution to $100 \% \mathrm{H}_{2} \mathrm{O}$ ), stained with

266 hematoxylin/eosin, rehydrated through a series of ethanol

267 washes (from $70 \%$ to $100 \%$ solution to $100 \%$ xylene), and

268 mounted with cover slides using DPX. Lesions were evaluated

269 under the microscope (Axio Imager, A1, Zeiss; objective EC

270 Plan-NEOFLUAR 20x/0.5, $/ 0.17)$, focusing on sensitive areas

271 such as the periportal spaces in both the liver and the

272 renal tubules as well as the glomeruli in the kidneys.

\section{Potential global effects on amphibians}

275 To quantify the potential spatial overlap of ants and 276 amphibians at a global scale we obtained a total of 1,407 277 geographic records on Argentine ant locations from the GBIF 
278 (Global Biodiversity Information Facility,

279 https://www.gbif.org), AntWeb (https://www.antweb.org, 280 AntWeb 2018) and GLAD (http://globalants.org/) websites.

281 Amphibian ranges and IUCN status were obtained from the IUCN 282 Red List (v. 2017-3, www.iucnredlist.org). We used the 283 function gContains in the $\mathrm{R}$ package rgeos (Bivand \& Rundel 2842017 ) to extract amphibian species whose distribution 285 polygons overlapped with the ranges of any given ant 286 population. We then filtered this list of species using IUCN 287 habitat categories to exclude amphibian species that did not 288 use similar macrohabitats as L. humile (Supporting 289 Information). Ants and amphibians may further be segregated by 291 differences in microhabitat use. We used the eight 292 categories of microhabitat, described in Moen \& Wiens 293 (2017), that adults use outside of the breeding period and 294 included species from our dataset (Supporting Information), 295 employing habitat descriptions from the IUCN Red List and 296 the AmphibiaWeb database (www.amphibiaweb.org). We excluded 297 any amphibian species that only occur in aquatic, semi298 aquatic, or torrential microhabitats, where L. humile is not 299 likely occur. Juvenile amphibians likely use slightly different 301 microhabitats from adults (Wells 2010; Duellman \& Trueb 302 1994). We therefore considered the full dataset to be the 
maximum number of possible amphibian species overlapping

304 spatially with the ants and the microhabitat-filtered list

305 to be the minimum. We acknowledge that we may overestimate 306 risk, which is not solely determined by spatial overlap.

307 Additionally, the ant's impact will depend on the amphibian

308 species' biological traits, such as anatomy, behavior, or 309 physiology.

From the full dataset, we determined amphibian species

311 richness per ant locality. Then, using both the full and

312 microhabitat-filtered datasets, summarized cumulative

313 species richness for amphibians co-occurring with ant

314 populations per continent or section of continent. Finally,

315 for each of these regions and for both datasets, we assessed

316 the proportion of amphibian species in the five different

317 IUCN Red List risk categories.

\section{Statistical analysis}

320 For analyses, we assumed that paralysis (either in the lab

321 or the field) is equivalent to death for a juvenile, because

322 it would ensue if the juvenile remained in the Argentine ant

323 area. We therefore analyzed the proportion of alive versus

324 paralyzed+dead individuals using a generalized linear model

325 employing a binomial distribution and a logit link function

326 (PROC Genmod, SAS 2008); we first tested whether there were 
327 differences among amphibian species and among ant species.

328 We secondly tested the effect of the ant species within each 329 amphibian species. In this case, we performed planned post330 hoc comparisons (using the contrast command in PROC Genmod, 331 SAS 2008), which compared the effect of L. humile to each of 332 the native species. In the foraging-arena exposure experiment, we explored differences in behavior of L. humile, A. senilis, and T. cf. nigerrimum towards juvenile amphibians. Time to amphibian discovery and the maximum number of ants found on the amphibians were analyzed using generalized linear models

338 employing a gamma distribution and a Poisson distribution, 339 respectively, and a logit link function (PROC Genmod, SAS 340 2008). Ant species and amphibian species were fixed

341 independent variables; the number of ants in the foraging 342 arena at the beginning of the trial and amphibian mass were 343 covariates (the latter was only used in the model with the 344 maximum number of ants). When the results were significant, 345 we performed post-hoc comparisons among ant species, as 346 explained above. To determine differences in iridomyrmecin quantities we 348 performed a general linear mixed-effects model (square root 349 transformed) between $L$. humile and T. cf. nigerrimum; 350 covariance within colonies was included as a random factor. 
351 The model was fitted using the lmer function in the $\mathrm{R}$

352 package lme4 (Bates et al. 2015).

353

The effect of toxic doses on amphibians (affected vs

354 unaffected) was analyzed using generalized linear models

355 employing a binomial distribution and a logit link function

356 (glm function in the $\mathrm{R}$ package stats, $\mathrm{R}$ Core Team 2016). Ant

357 number per gram of amphibian, ant species, and amphibian

358 species were the independent variables. The toxic dose,

359 represented by the number of ants per gram of amphibian

360 expected to elicit a toxic effect for each ant-amphibian

361 species pair, was calculated using the function dose.p in

362 the R package MASS (Venables \& Ripley 2002) from the dose-

363 response curves. Because iridomyrmecin quantities can vary

364 among sites (Choe et al. 2012) we focused on the ecological

365 "ant dose", not necessarily on the toxin dose.

366 Relationships between the concentration of iridomyrmecin

$367\left(\mu \mathrm{g} \cdot \mathrm{g}^{-1}\right.$ of juvenile) in the brain and the clinical

368 evaluation (affected vs unaffected) was tested using a

369 generalized linear model employing a binomial distribution

370 and a logit function (glm function in the R package stats, $\mathrm{R}$

371 Core Team 2016); the model took amphibian species into

372 account. Then, we examined the relationship (Im function in

373 the $\mathrm{R}$ package stats) between the concentrations of

374 iridomyrmecin ( $\mu \mathrm{g} \cdot \mathrm{g}^{-1}$ of juvenile; log transformed) in each

375 tissue and the quantity of iridomyrmecin $\left(\mu \mathrm{g} \cdot \mathrm{g}^{-1}\right.$ of 
376 juvenile) applied to each juvenile, which was estimated

377 based on the species-specific iridomyrmecin contents. We

378 also tested whether higher doses $\left(\mu \mathrm{g} \cdot \mathrm{g}^{-1}\right.$ of juvenile; log

379 transformed) corresponded to the presence of lesions in

380 amphibian tissues (liver and kidney); a general linear model

381 (PROC genmod, SAS 2008) was used for each tissue in which

382 the identity of the amphibian species was taken into

383 account.

384

385 RESULTS

386 Linepithema humile and juvenile amphibians overlap at the 387 local scale

388 Newly metamorphosed E. calamita toadlets emerging from the 389 temporary ponds in uninvaded areas overlapped with different 390 species of native ants. Toadlets emerging from invaded ponds 391 overlapped only with $L$. humile, which was the sole ant 392 species present. This ant was much more abundant during the 393 day compared to the abundance of native ants around 394 uninvaded ponds (Supporting Information).

Linepithema humile preys on and kills juvenile amphibians

397 During 2013-2018 we performed observation of emerging frogs

398 from ponds along the surveyed L. humile trails. The 
objectives were to evaluate the direction of the interaction

400 (not to quantify the impact on amphibian populations). We

401 observed a total of 46 dead H. meridionalis frogs (12 in

402 2013, 34 in 2014); 6 dead P. cultripes toadlets (3 in 2013,

4033 in 2018); 2 dead Iberian painted frogs (Discoglossus

404 galganoi; 2018); and 1 dead Iberian parsley frog (Pelodytes

405 ibericus; 2018). The ants preyed on the amphibians, which

406 ranged from being recently dead to being entirely eaten

407 (skeletons) (Supporting Information).

408

409 Linepithema humile aggressiveness in the ant-trail-exposure

410

experiment

411 There was a significant detrimental effect of $L$. humile on

412 juveniles, but neither of $A$. senilis nor $T$. nigerrimum $\left(X^{2}=\right.$

413 10.10, $\mathrm{p}=0.006, \mathrm{~N}=57$, for differences among ant species,

414 Fig. 1a). The effects observed -alive versus paralyzed+dead-

415 also significantly differed among amphibian species $\left(x^{2}=\right.$

$4166.10, p=0.013, N=57)$. Specifically, the effects of $L$.

417 humile differed from those of the two native ants in the

418 case of $P$. cultripes $\left(X^{2}=10.10, p=0.006, N=30 ;\right.$ planned

419 comparisons: $p=0.010$ in both cases), but not in the case

420 of $H$. meridionalis $\left(x^{2}=0.00, p=1.000, N=27\right)$, in which

421 none of the froglets was affected by the ants (they always

422 escaped). In the $L$. humile trails, $20 \%$ of the $P$. cultripes 
423 toadlets died and a further 20\% were initially paralyzed but 424 recovered after approximately $10 \mathrm{~min}$ (Fig. 1a).

425

426

Linepithema humile aggressiveness in the foraging-arena-

The native ant $A$. senilis was faster to discover the amphibians than the invasive ant L. humile $\left(\chi^{2}=27.0, \mathrm{p}<\right.$ $0.001, \mathrm{~N}=290 ; \mathrm{p}<0.001$ for all contrast with A. senilis). 431 Moreover, the amphibians were covered by significantly more 432 ants of $T$. cf. nigerrimum than of $L$. humile (mean $\pm \mathrm{SE}$ : $17.9 \pm 1.9$ ants vs $13.0 \pm 2.0$ ants, respectively; $\chi^{2}=$

434 177.22, $\mathrm{p}<0.001, \mathrm{~N}=284 ; \mathrm{p}<0.018$ for all contrasts with 435 T. cf. nigerrimum). Notwithstanding, while the attacks by $A$. 436 senilis or $T$. cf. nigerrimum had no obvious effect, those by 437 L. humile ultimately resulted in paralysis and death $\left(x^{2}=\right.$ $43888.56, \mathrm{p}<0.001, \mathrm{~N}=294$, for differences among ant 439 species, Fig 1b). The effects observed -alive versus 440 paralyzed+dead- were also significant among amphibian 441 species $\left(X^{2}=14.43, \mathrm{p}<0.001, \mathrm{~N}=294\right)$. The effects of $L$. 442 humile differed from those of the two native ants on $P$. 443 cultripes and on E. calamita $\left(x^{2}=44.31, \mathrm{p}<0.001, \mathrm{~N}=94\right.$; $444 x^{2}=39.74, \mathrm{p}<0.001, \mathrm{~N}=125$, respectively; planned 445 comparisons: $\mathrm{p}<0.001$ in all cases), but not on $H$. 446 meridionalis $\left(x^{2}=4.51, \mathrm{p}=0.105, \mathrm{~N}=75\right)$. Exposure to $\mathrm{L}$. 
447 humile caused the strongest effect on P. cultripes, with 53\%

448 of juveniles becoming paralyzed, and all but one died within

$44948 \mathrm{~h}$ post-trial ( $\mathrm{N}=30 ; \mathrm{Fig}$. 1b). For E. calamita, 38\% of

450 toadlets were paralyzed during exposure but they recovered

$451 \sim 10$ min later and only one died ( $\mathrm{N}=45 ;$ Fig. 1b). Finally,

$452 H$. meridionalis was the least affected, with only 8응 of

453 froglets paralyzed, all of which recovered within $10 \mathrm{~min}$ (N $454=25)$.

455

456 Iridomyrmecin quantities in Linepithema humile

457 Linepithema humile and T. cf. nigerrimum workers have highly

458 developed pygidial glands (Supporting Information).

459 Iridomyrmecin (isomer 1 ) is the main compound found in $L$.

460 humile pygidial glands. In T. cf. nigerrimum workers are

461 isomers of iridodial the main components, accompanied by

462 smaller amounts of iridomyrmecin (isomers 1 and 2;

463 Supporting Information). Although T. cf. nigerrimum workers

464 are slightly larger in body size than L. humile workers, the

465 latter contain five times more iridomyrmecin (mean $\pm \mathrm{SE}$ :

$4666.416 \pm 0.443 \mu \mathrm{g}$ VS $1.291 \pm 1.127 \mu \mathrm{g} ; \mathrm{F}=135.76, \mathrm{p}<0.0001$,

$467 \mathrm{~N}=100)$, representing $1.4 \%$ of worker fresh body mass in $L$.

468 humile compared to just $0.2 \%$ in $T$. cf. nigerrimum. 
470 Iridomyrmecin-exposure experiments and toxic doses

471 According to our quantification and assuming that the ants 472 eject all their pygidial gland content at once, the three 473 quantities of iridomyrmecin applied (0.1, 1, and $5 \mathrm{mg}$ ) are 474 equivalent, respectively, to average doses ( $\pm \mathrm{SE}$ ) ejected by $4758.4 \pm 1.2,69.7 \pm 6.4$, and $307.5 \pm 30.3$ L. humile workers/g 476 of juvenile. We observed significant differences among 477 treatments $\left(X^{2}=25.63, \mathrm{p}<0.001, \mathrm{~N}=42, \mathrm{Fig}\right.$. 1c). The 478 lower doses were not significantly different from the 479 control (no treatment, $\mathrm{p}>0.05$ ), with all individuals alive 480 at the end of the experiment. However, the highest dose was 481 different $(\mathrm{p}<0.001)$, causing paralysis in $70 \%$ of the 482 juveniles.

483 Amphibians were increasingly affected by greater

484 numbers of ants in a dose-dependent manner $\left(\chi^{2}=26.69, \mathrm{p}<\right.$ $4850.001, \mathrm{~N}=81)$. However, the magnitude of the effect 486 differed, depending on both amphibian species and ant 487 species $\left(\chi^{2}=23.40, \mathrm{p}<0.001, \mathrm{~N}=81\right.$ and $\chi^{2}=22.92, \mathrm{p}<$ $4880.001, N=81$, respectively; Fig. 2a). Comparatively, 489 smaller numbers of $L$. humile caused more dramatic negative 490 consequences than did larger numbers of T. cf. nigerrimum $491 \quad$ (Fig. 2b) . 
493 Iridomyrmecin causes general paralysis and histological

494 lesions

495 Results of the laboratory evaluations showed that the venom

496 of the invasive ant $L$. humile had neurological effects,

497 specifically in the medulla oblongata, pontine nucleus, and

498 midbrain. The venom caused general paralysis (Fig. 3a),

499 sometimes accompanied by extraocular paralysis, loss of

500 photopupillary and palpebral reflexes, and loss of

501 nociception response. We also observed severe damage to the

502 skin of juveniles that came in contact with $L$. humile and of

503 juveniles treated with iridomyrmecin (Fig. 3b) .

$504 \quad$ Neurological affected individuals had higher levels of

505 iridomyrmecin in their brains than did unaffected

506 individuals $\left(\chi^{2}=10.19, \mathrm{p}=0.001, \mathrm{~N}=28\right)$. Moreover,

507 concentrations of iridomyrmecin in brain, liver, and kidney

508 tissue were significantly correlated with the equivalent

509 amounts of iridomyrmecin applied (brain: $\mathrm{F}=17.69, \mathrm{p}<$

$5100.001, \mathrm{~N}=28$; liver: $\mathrm{F}=14.24, \mathrm{p}<0.001, \mathrm{~N}=27$; kidney:

$511 \mathrm{~F}=8.29, \mathrm{p}=0.008, \mathrm{~N}=26 ; \mathrm{Fig} \cdot 3 \mathrm{c})$.

512 The histological samples revealed liver and kidney

513 damage, indicating the toxin's acute effects on these

514 tissues. In the liver, we found inflammatory cell

515 infiltrates (heterophils) around the hepatic artery (Fig.

$5163 d, e)$. These lesions were observed in 16 cases $(\mathrm{N}=33$, all

517 species combined). There was no significant relationship 
518 between the quantity of iridomyrmecin per gram of amphibian

519 and the presence of lesions $\left(\chi^{2}=0.12, \mathrm{p}=0.727, \mathrm{~N}=33\right)$,

520 which could be due to the individuals' short exposure to the

521 toxin (only $10 \mathrm{~min}$; see Methods). In the kidney, we found

522 inflammatory cell infiltrates (lympho-plasmocitary cells) in

523 the renal tubules, which indicated tubulo-interstitial

524 nephritis (Fig. 3f, g). There were lesions in just five

525 cases ( $N=32$, all species combined); these were found in

526 individuals who had received mean doses of $0.674,0.665$, and

$5271.167 \mathrm{mg}$ of iridomyrmecin per gram of amphibian for $E$.

528 calamita, $P$. cultripes, and $H$. meridionalis, respectively.

530 Potential global impacts on amphibians

531 We examined the overlap across the globe between the

532 distribution ranges of amphibian species and the locations

533 of 1,407 L. humile populations, 61 of which were native,

534 while the rest were invasive. There were only $51 \mathrm{~L}$. humile

535 populations (all invasive) that were not associated with any 536 amphibians.

537 Using the full dataset, we determined that, worldwide,

538 L. humile populations co-occurred with a total of 813

539 amphibian species (based on the 6,513 terrestrial amphibian

540 species with spatial data in the IUCN Red List database),

541 and only 9 of these amphibians exclusively co-occurred with 
542 native L. humile populations. Outside of its native range,

543 L. humile potentially co-occurs with a mean ( \pm SE) of 11.06

$544( \pm 0.23)$ amphibian species per locality (range: 1-86, $\mathrm{N}=$

545 1295; Fig. 4). When filtering the amphibian species by

546 microhabitat, L. humile populations co-occurred with a total

547 of 693 amphibian species, and, with a mean ( \pm SE) of 7.22 ( \pm

548 0.20) amphibian species per locality (range: $1-78, \mathrm{~N}=1287$ )

549 outside its native range.

550

551 DISCUSSION

552 Here, we provide empirical evidence demonstrating the

553 detrimental effect of L. humile ants, through their

554 iridomyrmecin toxin, in killing juvenile terrestrial

555 amphibians. The effect is dose- and species-dependent, and

556 specific to L. humile. Although the three tested amphibian

557 species are listed as of least concern (H. meridionalis and

558 E. calamita) and near-threatened (P. cultripes;

559 https://www.iucnredlist.org), they represent a broad

560 phylogenetic spectrum and some of the most geographically

561 widespread families. Worldwide, a total of 813 amphibian

562 species overlap in range and macrohabitat with the Argentine

563 ant and could therefore be affected by the species' chemical

564 weaponry. Of these species, $6.27 \%$ are classified as

565 threatened by IUCN. At the regional level, this percentage

566 is as high as $16.39 \%$ (in Australia). 

Although the most tolerant $H$. meridionalis was able to

568 escape from the ant trails in the field soon after contact, 569 more subtle effects were observed when confined with the 570 ants for longer periods. These findings suggest that, unlike 571 the two other amphibian species, the jumping behavior of 572 this frog could enable its quicker escape. Similar escape 573 behavioral strategies have been described for juvenile 574 Sceloporus undulatus lizards when encountering the red 575 imported fire ant S. invicta (Langkilde et al. 2009). 576 Moreover, juveniles of several Hyla species were observed 577 feeding on Argentine ants without any apparent negative effects (although the researchers did not look for them; Ito et al. 2009), hinting at further tolerance. The dose-response experiments confirmed the high susceptibility of $E$. calamita and $P$. cultripes toadlets to I. humile attack. For example, E. calamita, exhibiting a mean mass ( $\pm \mathrm{SE})$ of $0.45 \pm 0.05 \mathrm{~g}$ after metamorphosis, required only 20 attacking $L$. humile to result in a detrimental effect. In contrast, more than 150 workers of the native ant $T$. cf. nigerrimum would have been required to

587 achieve such an effect. We attribute this difference to the larger quantities of 588 iridomyrmecin in $L$. humile compared to in $T$. cf. nigerrimum. 589 Besides its greater toxicity, the augmented threat from L. humile arise 590 from its high abundance and monopolization of invaded areas, e.g., around ponds 591 (Angulo et al. 2011; Alvarez-Blanco et al. 2017). Consequently, emerging E. calamita 
592 have little chances of surviving in ant invaded areas. Moreover, this species is also

593 especially sensitive to other drivers of global change, such as climate warming (Bosch et

594 al. 2018).

The role of $L$. humile as a predator is not apparent and

ill studied. It is mostly considered as scavenger (Angulo et al.

597 2011), and reports on its predation habits are scanty (Suarez et al. 2005). This is 598 probably due to the lack of a functional sting and the

599 ineffectiveness of its venom to humans or mammals (Pavan \& Ronchetti 1955).

600 Moreover, it may have a delayed detrimental effect on amphibians, thus there is no

601 obvious association between their death and the ants.

602

The iridomyrmecin-exposure experiment revealed its high

603 toxicity to amphibians, indicating that L. humile can cause amphibian

604 mortality, and describes the proximate mechanisms involved

605 (behavioral and chemical). Understanding the mechanisms that

606

underlie the impacts of invasive species helps scientists to

607

assess their potential magnitude, which is essential when

608

prioritizing and managing invasions, as made clear in the

609 Aichi targets of the Convention of Biological Diversity

610 (Strategic Plan 2020,

611 www.cbd.int/sp/targets/rationale/target-9). Here we reveal

612 the potential magnitude of this impact, based on the global

613 spread of the Argentine ant (Bertelsmeier et al. 2018), and

614 when acting together with other drivers of amphibian decline

615 (Grant et al. 2016). We highlight the need for new research along two broad

616 lines: determining the factors underlying venom toxicity to other amphibians (e.g., skin 
617 permeability or life-history traits, such as developmental type or breeding strategy); and

618 examining whether the venom effect could scale to demographic effects (because

619 population persistence is highly sensitive to the survival of juveniles in pond-breeding 620 amphibians, Pittman et al. 2014), in order to accurately understand and contend with the 621 worldwide impact of this invasive ant on amphibians.

622

\section{Supporting Information}

624

Extended information on methods (Appendix S1), the

625 functional ecology of iridomyrmecin (Appendix S2), the

626 temporal and spatial overlap of $L$. humile ants with

627 amphibians (Appendix S3), the identification of L. humile 628 venom (Appendix S4), and the list of amphibian species 629 across the globe overlapping with I. humile populations 630 (Appendix S5) are available online. The authors are solely responsible for the content and functionality of these materials. Queries (other than absence of the material)

633 should be directed to the corresponding author.

634

635 Literature Cited

636 Allen CR, Epperson DM, Garmestani AS. 2004. Red imported 637 fire ant impacts on wildlife: a decade of research. The 638 American Midland Naturalist 152:88-103. 
639 Alvarez-Blanco P, Caut S, Cerdá X, Angulo E. 2017. Native

640 predators living in invaded areas: responses of

641 terrestrial amphibian species to an Argentine ant

642 invasion. Oecologia 185:95-106.

643 Arnan X, Cerdá X, Retana J. 2012. Distinctive life traits

644 and distribution along environmental gradients of

645 dominant and subordinate Mediterranean ant species.

646 Oecologia 170:489-500.

647 Attygalle AB, \& Morgan ED. 1984. Chemicals from the glands

648 of ants. Chemical Society Reviews 13:245-278.

649 Bates D, Maechler M, Bolker B, Walker S. 2015. Fitting

$650 \quad$ linear mixed-effects models using lme4. Journal of

$651 \quad$ Statistical Software 67:1-48.

652 Bertelsmeier C, Ollier S, Liebhold AM, Brockerhoff EG, Ward

653 D, Keller L. 2018. Recurrent bridgehead effects

654 accelerate global alien ant spread. Proceedings of the

655 National Academy of Sciences 115: 5486-5491.

656 Betts, J., Young, R. P., Hilton-Taylor, C., Hoffmann, M.,

657 Rodríguez, J. P., Stuart, S. N., \& Milner-Gulland, E. J.

658 In press. A framework for evaluating the impact of the

659 IUCN Red List of threatened species. Conservation

660 Biology. 
661 Bivand R, Rundel C. 2017. rgeos: Interface to Geometry

662 Engine - Open Source ('GEOS'). R package version 0.3-26.

663 https://CRAN.R-project.org/package=rgeos

664 Blaustein AR, Kiesecker JM. 2002. Complexity in

665 conservation: lessons from the global decline of

666 amphibian populations. Ecology Letters 5:597-608.

667 Blum MS. 1996. Semiochemical parsimony in the Arthropoda.

668 Annual Review of Entomology 41:353-374.

669 Bosch J, Fernández-Beaskoetxea S, Garner TW, Carrascal LM.

670 2018. Long term monitoring of an amphibian community after

671 a climate change and infectious diseasedriven species

672 extirpation. Global Change Biology 24:2622-2632.

673 Cavill GWK, Houghton E, McDonald FJ, Williams PJ. 1976.

674 Isolation and characterization of dolichodial and related

675 compounds from the Argentine ant, Iridomyrmex humilis.

676 Insect Biochemistry 6:483-490.

677 Chauhan KR, Schmidt W. 2014. Biorational synthesis of

678 iridomyrmecin diastereomers from catnip oil. Tetrahedron

679 Letters 55:2534-2536.

680 Choe DH, Villafuerte DB, Tsutsui ND. 2012. Trail pheromone

681 of the argentine ant, Linepithema humile

682 (Mayr) (Hymenoptera: Formicidae). PLoS One 7:e45016. 
683 Díaz-Paniagua C, et al. 2010. Temporay ponds from Doñana

684 National Park: a system of natural habitats for the 685 preservation of aquatic flora and fauna. Limnetica 29:4168658.

687 Duellman WE, Trueb L. 1994. Biology of amphibians. JHU 688 press.

689 Grant EHC, et al. 2016. Quantitative evidence for the 690 effects of multiple drivers on continental-scale 691 amphibian declines. Scientific Reports 6:25625.

692 Hof C, Araújo MB, Jetz W, Rahbek C. 2011. Additive threats 693 from pathogens, climate and land-use change for global 694 amphibian diversity. Nature 480:516-519.

695 Holway DA, Lach L, Suarez AV, Tsutsui ND, Case TJ. 2002. The 696 causes and consequences of ant invasions. Annual Review 697 of Ecology and Systematics 33:181-233.

698 Ito F, Okaue M, Ichikawa T. 2009. A note on prey composition 699 of the Japanese treefrog, Hyla japonica, in an area 700 invaded by Argentine ants, Linepithema humile, in 701 Hiroshima prefecture, western Japan (Hymenoptera: 702 Formicidae). Myrmecological News 12:35-39.

703 Kats LB, Ferrer RP. 2003. Alien predators and amphibian 704 declines: review of two decades of science and the 705 transition to conservation. Diversity and Distributions, $7069: 99-110$. 
707 Kiesecker JM, Blaustein AR, Belden LK. 2001. Complex causes 708 of amphibian population declines. Nature Methods 410:681709684.

710 Langkilde T. 2009. Invasive fire ants alter behavior and 711 morphology of native lizards. Ecology 90:208-217.

712 Moen DS, Wiens JJ. 2017 Microhabitat and climatic niche 713 change explain patterns of diversification among frog 714 families. The American Naturalist 190:29-44.

715 Pavan M, Ronchetti G. 1955. Studi sulla morfologia esterna e 716 anatomia interna dell'operaia di Iridomyrmex humilis Mayr 717 e ricerche chimiche e biologiche sulla iridomirmecina. 718 Atti Soc It Sc Nat 94:379-477.

719 Pittman S, Osbourn M, Semlitsch R. 2014. Movement ecology of 720 amphibians: a missing component for understanding 721 population declines. Biological Conservation 169:44-53.

722 R Core Team. 2016. R: A language and environment for 723 statistical computing. R Foundation for statistical 724 Computing, Vienna, Austria.

725 SAS/STAT® 2008. 9.2 User's Guide SAS Inst, Cary, NC.

726 Strategic Plan 2020, target 9.

727 https://www.cbd.int/sp/targets. (Accessed May 2020).

728 Stuart SN, Chanson JS, Cox NA, Young BE, Rodrigues ASL, 729 Fischman DL, Waller RW. 2004. Status and trends of 

amphibian declines and extinctions worldwide. Science, $731 \quad 306: 1783-1786$.

732 Suarez AV, Case TJ. 2002. Bottom-up effects on persistence 733 of a specialist predator: Ant invasions and horned 734 lizards. Ecological Applications 12:291-298.

735 Suarez A, Yeh P, Case TJ. 2005 Impacts of Argentine ants on 736 avian nesting success. Insectes Sociaux 52:378-382.

737 Venables WN, Ripley BD. 2002. Modern Applied Statistics with 738 S, Fourth Edition ed. Springer, New York.

739 Wells KD. 2010. The ecology and behavior of amphibians. $740 \quad$ University of Chicago Press.

741 Welzel KF, Lee SH, Dossey AT, Chauhan KR, Choe D-H. 2018.

742 Verification of Argentine ant defensive compounds and 743 their behavioral effects on heterospecific competitors 744 and conspecific nestmates. Scientific Reports 8:1477.

\section{Data accessibility}

747 Data will be deposited in the institutional repository. 


\section{Figure legends (in color for online version)}

750 FIGURE 1 . Effects of ant contact and iridomyrmecin on

751 juvenile amphibians. (a) Effects on juveniles of two

752 amphibian species that spent $2-10 \mathrm{~min}$ in contact with ants

753 on their trails in the field. (b) Effects on juveniles of

754 three amphibian species that spent up to $10 \mathrm{~min}$ in contact

755 with ants in the foraging arenas of laboratory nests. (c)

756 Effects on Pelobates cultripes toadlets whose backs were

757 rubbed with three different concentrations of iridomyrmecin

$758(0.1,1$, or $5 \mathrm{mg} /$ toadlet, equivalent to $8.15 \pm 1.13,67.86 \pm$

7596.78 , or $307.62 \pm 30.30$ Linepithema humile workers/g of

760 toadlet; mean $\pm \mathrm{SE})$. Sample size is indicated in the center

761 of each pie chart.

762

763 FIGURE 2. Dose-response curves for three amphibian species

764 (ant numbers per $g$ of juvenile amphibian): Epidalea calamita

765 (red), Pelobates cultripes (blue), and Hyla meridionalis

766 (green). (a) Numbers of amphibians that were affected (1) or

767 unaffected (0) (normal or abnormal reactions observed during

768 clinical evaluation, see Methods) 10 min after application

769 of mashes of different numbers of ants of the invasive $L$.

770 humile (straight lines/circles) or the native Tapinoma cf.

771 nigerrimum (dashed lines/triangles). (b) Toxic dose,

772 comprising the mean number \pm SE of ants (and the equivalent 
amount in $\mathrm{mg} \pm \mathrm{SE}$ of iridomyrmecin) per $\mathrm{g}$ of juvenile

774 amphibian that elicited an effect. SE are only shown when

775 meaningful. Equivalent amounts of iridomyrmecin were

776 calculated using the species-specific contents: $6.416 \pm$

$7770.443 \mu \mathrm{g}$ for $L$. humile and $1.291 \pm 1.127 \mu \mathrm{g}$ for $\mathrm{T}$. Cf.

778 nigerrimum.

779

780

781

782

783

784

785

786

787

788

789

790

791

792

793

794

795

796

\section{Figure 3. Effects of iridomyrmecin on toadlets and toadlet}

tissues. Pelobates cultripes toadlet with (a) an abnormal motor response (ataxia, paresis, and flaccidity) and with skin ulcers (marked with an arrow).

(c) Relationship between the dose applied (equivalent amounts of iridomyrmecin estimated from the number of Linepithema humile [in red] or Tapinoma cf. nigerrimum [in blue] applied to toadlets) and the concentration of iridomyrmecin measured in toadlet tissues after treatment. Model fit was determined using the combined data for all the amphibian species and ant species. (d) Unaffected liver. (e) Damaged liver with lymphoplasmocytic inflammatory infiltrates in the periportal space (circled). (f) Unaffected kidney. (g) Damaged kidney with acute tubulo-interstitial nephritis (marked with arrows). 
798 Figure 4. World map showing records of native and invasive

799 I. humile populations (native range in light blue). Point

800 color reflects the number of co-occurring amphibian species

801 (1:green to 86:red; 0: gray) based on spatial and

802 macrohabitat overlap, and the pie charts show regional

803 species richness (range of cumulative number of species for

804 the full dataset [top] and for the microhabitat-filtered

805 dataset [bottom]) and the proportion of species in non-

806 threatened (black) and threatened (gray) IUCN Red List

807 categories (for full dataset). The following regions were

808 defined: the native range of $L$. humile, the rest of south

809 America, North America (plus Japan), Europe (including

810 European island colonies in North Africa), Sub-Saharan

811 Africa, and Oceania. The bar charts for each region show the

812 number of species that are vulnerable (VU), endangered (EN),

813 and critically endangered (CR) for both the full (hashed)

814 and microhabitat-filtered (filled) datasets. 


\section{Figure legends (black and white for printed}

817 version)

818 FIGURE 1. Effects of ant contact and iridomyrmecin on

819 juvenile amphibians. (a) Effects on juveniles of two

820 amphibian species that spent 2-10 min in contact with ants

821 on their trails in the field. (b) Effects on juveniles of

822 three amphibian species that spent up to $10 \mathrm{~min}$ in contact

823 with ants in the foraging arenas of laboratory nests. (c)

824 Effects on Pelobates cultripes toadlets whose backs were

825 rubbed with three different concentrations of iridomyrmecin

$826(0.1,1$, or $5 \mathrm{mg} /$ toadlet, equivalent to $8.15 \pm 1.13,67.86 \pm$

8276.78 , or $307.62 \pm 30.30$ Linepithema humile workers/g of

828 toadlet; mean $\pm \mathrm{SE})$. Sample size is indicated in the center

829 of each pie chart.

830

831 FIGURE 2. Dose-response curves for three amphibian species

832 (ant numbers per g of juvenile amphibian): Epidalea calamita

833 (black), Pelobates cultripes (dark gray), and Hyla

834 meridionalis (light gray). (a) Numbers of amphibians that

835 were affected (1) or unaffected (0) (normal or abnormal

836 reactions observed during clinical evaluation, see Methods)

83710 min after application of mashes of different numbers of

838 ants of the invasive L. humile (straight lines/circles) or

839 the native Tapinoma cf. nigerrimum (dashed lines/triangles). 
840 (b) Toxic dose, comprising the mean number \pm SE of ants (and 841 the equivalent amount in $\mathrm{mg} \pm \mathrm{SE}$ of iridomyrmecin) per $\mathrm{g}$ of 842 juvenile amphibian that elicited an effect. SE are only

843 shown when meaningful. Equivalent amounts of iridomyrmecin

844 were calculated using the species-specific contents: $6.416 \pm$ $8450.443 \mu \mathrm{g}$ for $\mathrm{L}$. humile and $1.291 \pm 1.127 \mu \mathrm{g}$ for $T$. cf. 846 nigerrimum.

Figure 3. Effects of iridomyrmecin on toadlets and toadlet

849 tissues. Pelobates cultripes toadlet with (a) an abnormal motor response (ataxia, paresis, and flaccidity) and

851 with skin ulcers (marked with an arrow). (c) Relationship

852 between the dose applied (equivalent amounts of

853 iridomyrmecin estimated from the number of Linepithema 854 humile [in black] or Tapinoma cf. nigerrimum [in white] 855 applied to toadlets) and the concentration of iridomyrmecin 856 measured in toadlet tissues after treatment. Model fit was 857 determined using the combined data for all the amphibian 858 species and ant species. (d)

(d) Unaffected liver.

(e) Damaged

859 liver with lymphoplasmocytic inflammatory infiltrates in the 860 periportal space (circled). (f) Unaffected kidney.

861 Damaged kidney with acute tubulo-interstitial nephritis 862 (marked with arrows). 
864 Figure 4. World map showing records of native and invasive

865 L. humile populations. Point color reflects the number of

866 co-occurring amphibian species (1:white to 86:black;

867 0:hollow, gray outline only) based on spatial and

868 macrohabitat overlap, and the pie charts show regional

869 species richness (range of cumulative number of species for

870 the full dataset [top] and for the microhabitat-filtered

871 dataset [bottom]) and the proportion of species in non-

872 threatened (black) and threatened (gray) IUCN Red List

873 categories (for full dataset). The following regions were

874 defined: the native range of $\mathrm{L}$. humile, the rest of south

875 America, North America (plus Japan), Europe (including

876 European island colonies in North Africa), Sub-Saharan

877 Africa, and Oceania. The bar charts for each region show the

878 number of species that are vulnerable (VU), endangered (EN),

879 and critically endangered (CR) for both the full (hashed)

880 and microhabitat-filtered (filled) datasets. 


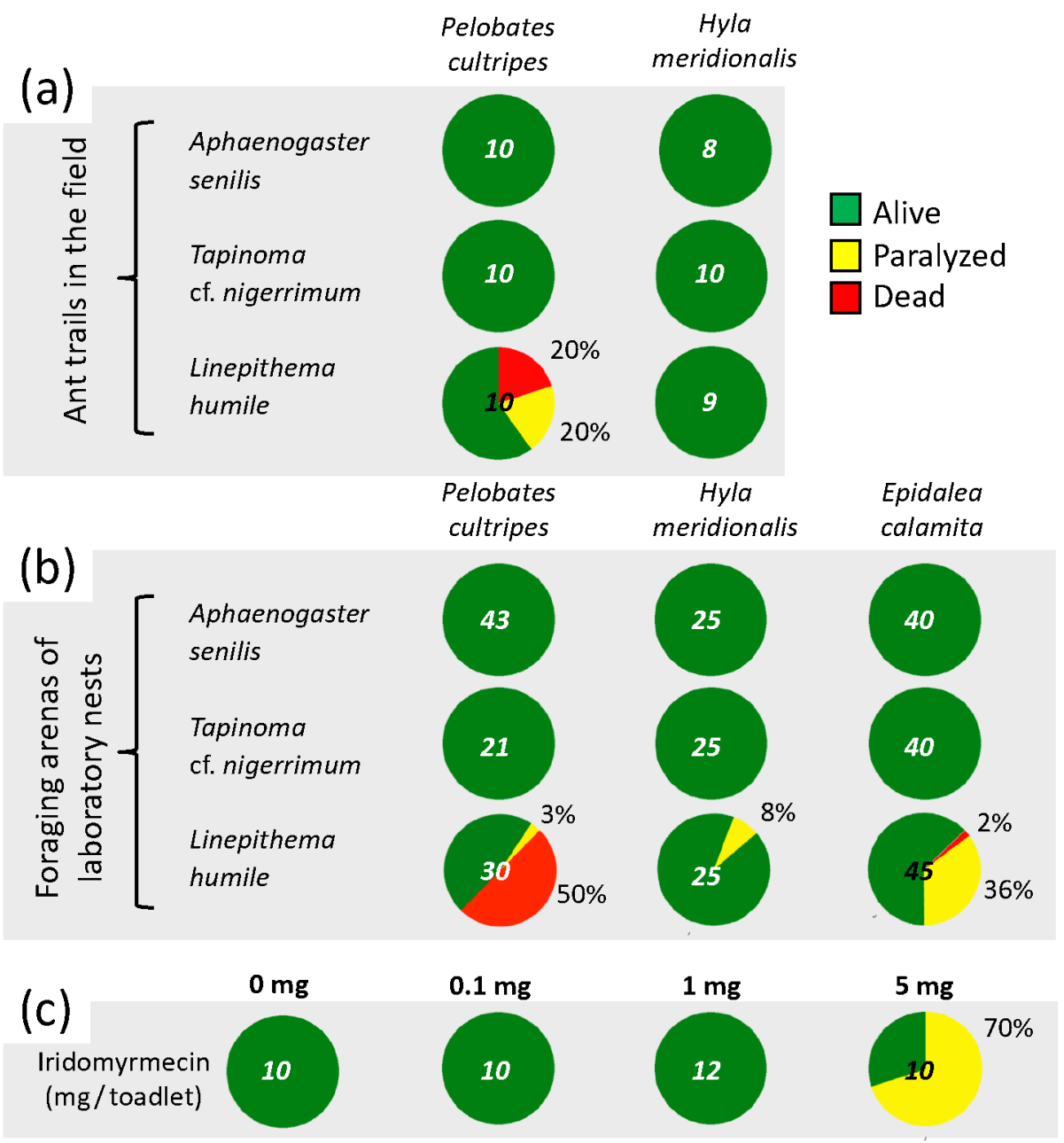

Figure 1. Effects of ant contact and ant chemicals on juvenile amphibians. (a) Effects on juveniles of two amphibian species that spent 2-10 min in contact with ants on ant trails in the field; (b) Effects on juveniles of three amphibian species that spent up to 10 min in contact with ants in the foraging arenas of laboratory nests; (c) Effects on Pelobates cultripes toadlets whose backs were rubbed with three different concentrations of iridomyrmecin $(0.1,1$, or $5 \mathrm{mg} /$ toadlet, which was equivalent to 8.15 $\pm 1.13,67.86 \pm 6.78$, or $307.62 \pm 30.30$ Linepithema humile workers/g of toadlet; mean \pm SE). Sample size is indicated in the center of each pie chart. 
(a)

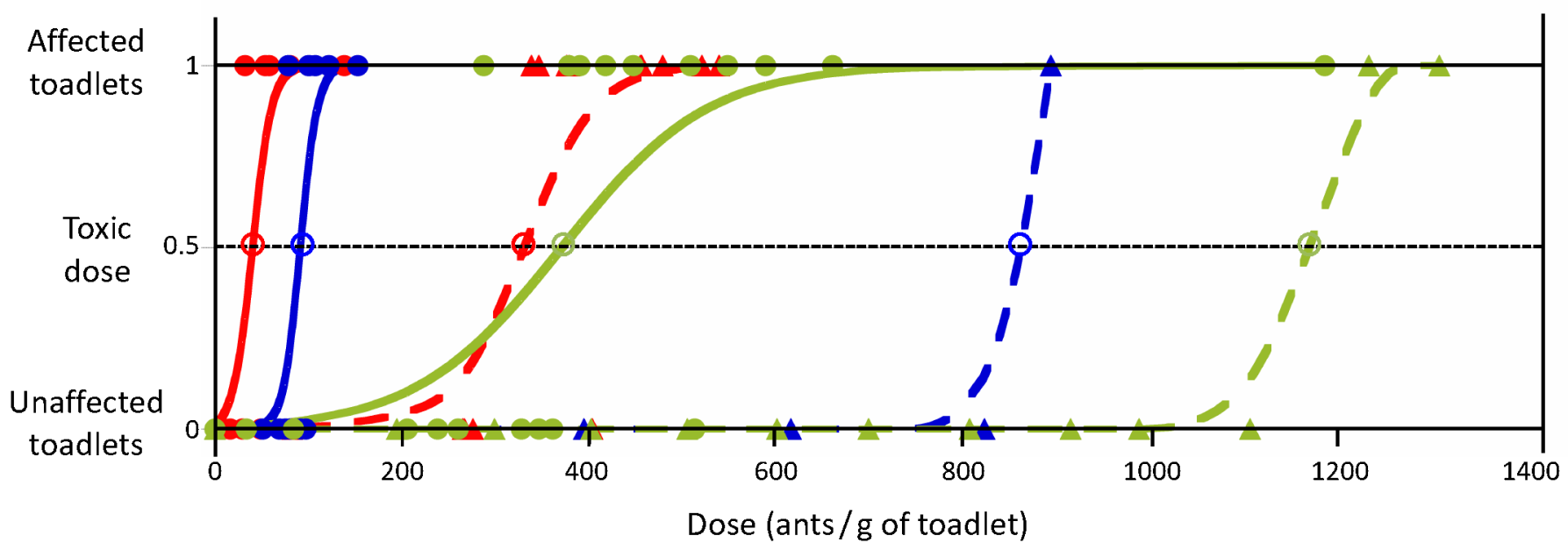

(b)

\begin{tabular}{|c|c|c|c|c|}
\hline \multirow[t]{2}{*}{ TOXIC DOSE } & \multicolumn{2}{|c|}{ Number of ants / $\mathrm{g}$ toadlet } & \multicolumn{2}{|c|}{ mg iridomyrmecin / g toadlet } \\
\hline & L. humile & T. cf. nigerrimum & L. humile & T. cf. nigerrimum \\
\hline Epidalea calamita & $40.1 \pm 9.5$ & $328.0 \pm 29.9$ & $0.257 \pm 0.061$ & $0.423 \pm 0.039$ \\
\hline Pelobates cultripes & $90.6 \pm 6.5$ & -849.7 & $0.582 \pm 0.042$ & 1.097 \\
\hline Hyla meridionalis & $367.8 \pm 44.5$ & 1158.5 & $2.360 \pm 0.285$ & 1.496 \\
\hline
\end{tabular}

Figure 2. Dose-response curves for three amphibian species (ant numbers per g of juvenile amphibian): Epidalea calamita (red), Pelobates cultripes (blue), and Hyla meridionalis (green). (a), Numbers of amphibians who were affected (1) or unaffected (0) (normal or abnormal reaction observed during clinical evaluation, see Methods) after spending $10 \mathrm{~min}$ in contact with a mash of different numbers of ants of the invasive Linepithema humile (straight lines/circles) or the native Tapinoma cf. nigerrimum (dashed lines/triangles). (b) Toxic dose, which was the mean number \pm SE of ants (and the equivalent amount in $\mathrm{mg}$ \pm SE of iridomyrmecin) per $g$ of juvenile amphibian that elicited an effect. SE are only shown when meaningful. Equivalent amounts of iridomyrmecin were calculated using the species-specific contents: 6.416 $\pm 0.443 \mathrm{mg}$ for $L$. humile and $1.291 \pm 1.127 \mathrm{mg}$ for $T$. cf. nigerrimum. 

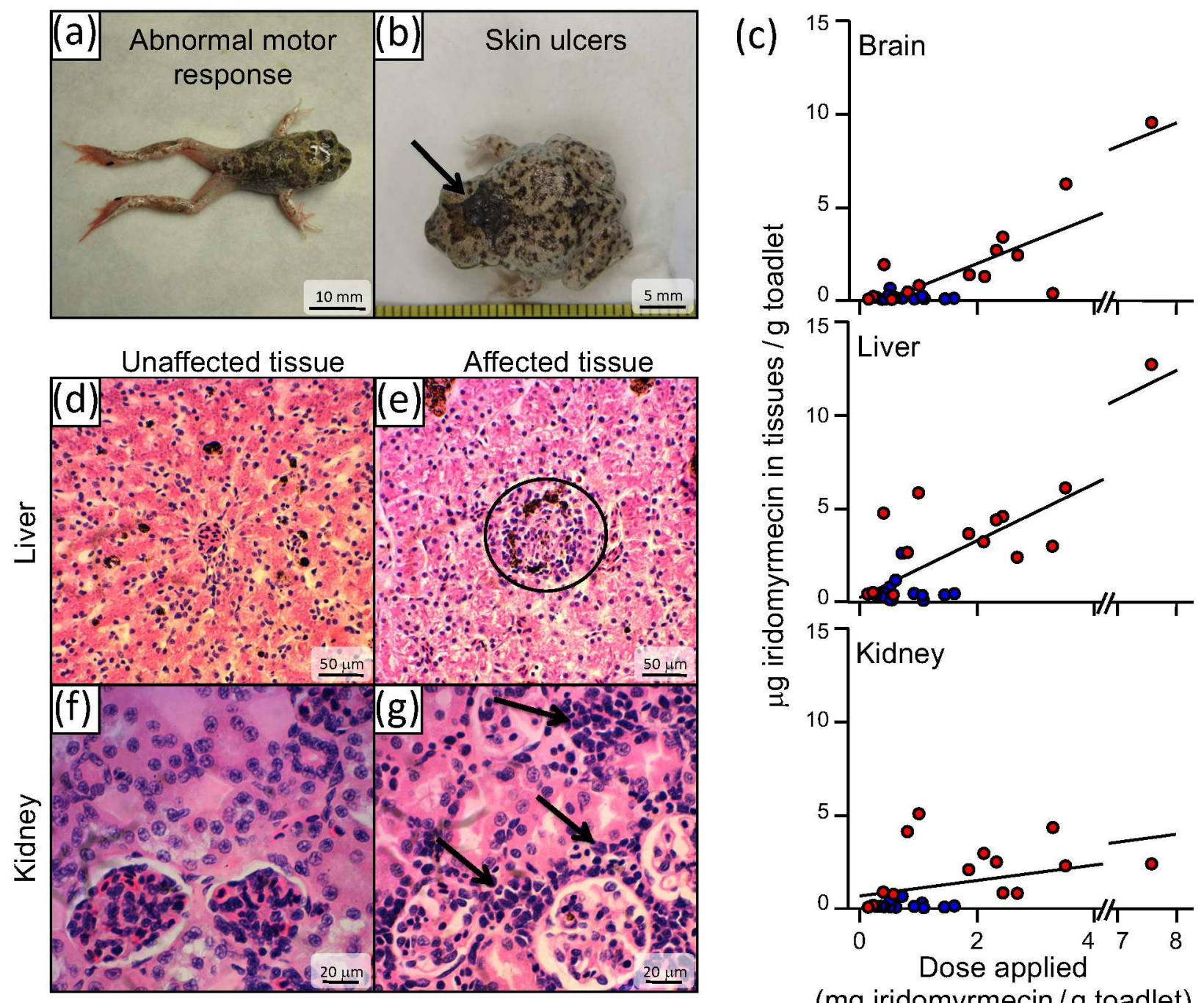

(mg iridomyrmecin /g toadlet)

Figure 3. Effects of iridomyrmecin on toadlets and toadlet tissues. Pelobates cultripes toadlet with (a) an abnormal motor response (ataxia, paresis, and flaccidity) and (b) with skin ulcers (marked with an arrow). (c) Relationship between the dose applied (equivalent amounts of iridomyrmecin estimated from the number of Linepithema humile [in red] or Tapinoma cf. nigerrimum [in blue] applied to toadlets) and the concentration of iridomyrmecin measured in toadlet tissues after treatment. Model fit was determined using the combined data for all the amphibian species and ant species. (d) Unaffected liver. (e) Damaged liver with lymphoplasmocytic inflammatory infiltrates in the periportal space (circled). (f) Unaffected kidney. (g) Damaged kidney with acute tubulo-interstitial nephritis (marked with arrows). 


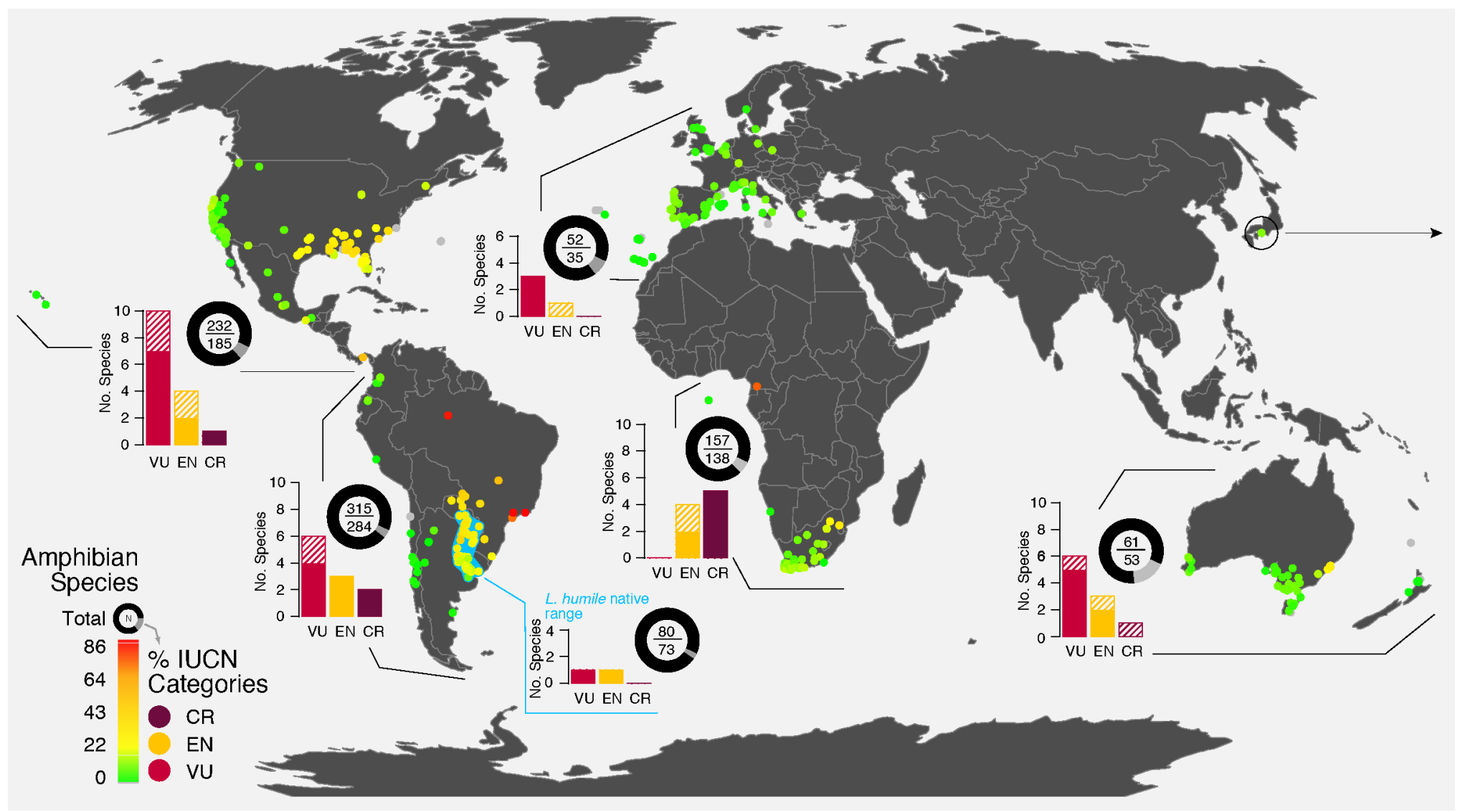


Figure 4. World map showing records of native and invasive $L$. humile populations (native range in light blue). Point color reflects the number of co-occurring amphibian species (1:green to 86:red; 0: grey) based on spatial and macrohabitat overlap, and the pie charts show regional species richness (range of cumulative number of species for the full dataset [top] and for the microhabitat-filtered dataset [bottom]) and the proportion of species in non-threatened (black) and threatened (gray) IUCN Red List categories (for full dataset). The following regions were defined: the native range of $L$. humile, the rest of South America, North America (plus Japan), Europe (including European island colonies in North Africa), Sub-Saharan Africa, and Oceania. The bar charts for each region show the number of species that are vulnerable (VU), endangered (EN), and critically endangered (CR) for both the full (hashed) and microhabitat-filtered (filled) datasets. 


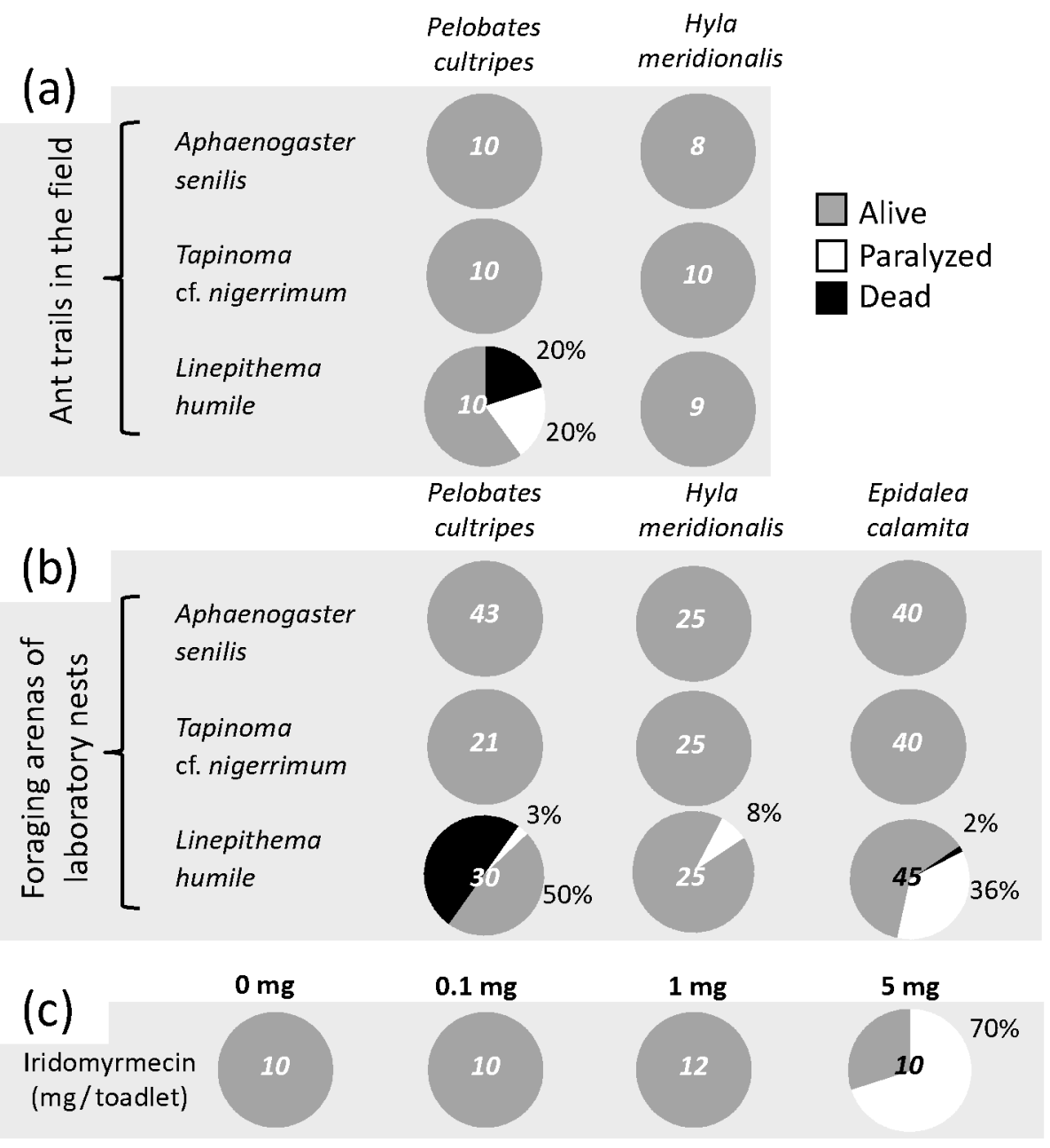

Figure 1. Effects of ant contact and ant chemicals on juvenile amphibians. (a) Effects on juveniles of two amphibian species that spent 2-10 min in contact with ants on ant trails in the field; (b) Effects on juveniles of three amphibian species that spent 10 min in contact with ants in the foraging arenas of laboratory nests; (c) Effects on Pelobates cultripes toadlets whose backs were rubbed with three different concentrations of iridomyrmecin $(0.1,1$, or $5 \mathrm{mg} /$ toadlet, which was equivalent to 8.15 $\pm 1.13,67.86 \pm 6.78$, or $307.62 \pm 30.30$ Linepithema humile workers/g of toadlet; mean $\pm \mathrm{SE}$ ). Sample size is indicated in the center of each pie chart. 
(a)

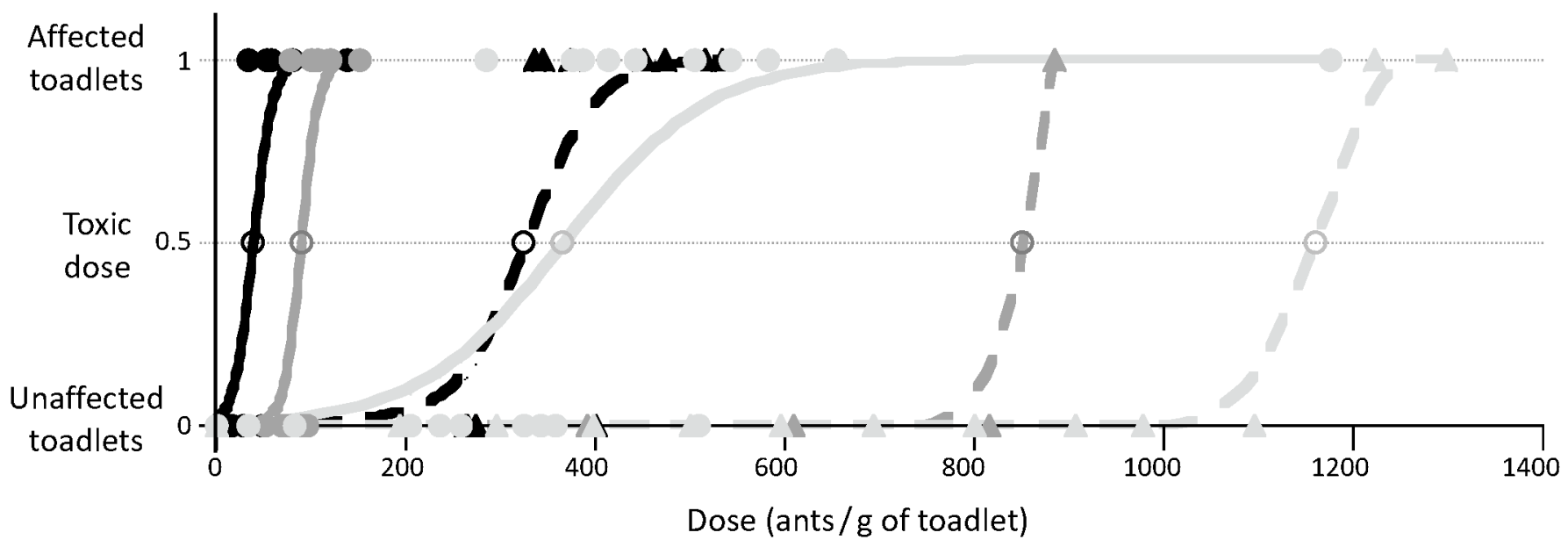

(b)

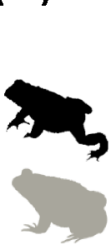

TOXIC DOSE

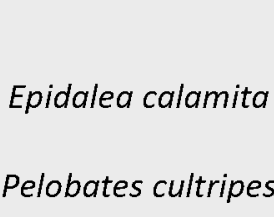

Hyla meridionalis
Number of ants / $\mathrm{g}$ toadlet

\begin{tabular}{cc}
\hline L. humile & $T$. cf. nigerrimum \\
\hline $\mathbf{4 0 . 1 \pm 9 . 5}$ & $328.0 \pm 29.9$
\end{tabular}

849.7

$90.6 \pm 6.5$ $367.8 \pm 44.5$

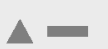

1158.5 $\mathrm{mg}$ iridomyrmecin / g toadlet

\begin{tabular}{cc}
\hline L. humile & T. cf. nigerrimum \\
\hline $0.257 \pm 0.061$ & $0.423 \pm 0.039$
\end{tabular}

$0.582 \pm 0.042$

1.097

$2.360 \pm 0.285$

1.496

Figure 2. Dose-response curves for three amphibian species (ant numbers per g of juvenile amphibian): Epidalea calamita (black), Pelobates cultripes (dark grey), and Hyla meridionalis (light grey). (a), Numbers of amphibians who were affected (1) or unaffected (0) (normal or abnormal reaction observed during clinical evaluation, see Methods) after spending $10 \mathrm{~min}$ in contact with a mash of different numbers of ants of the invasive Linepithema humile (straight lines/circles) or the native Tapinoma cf. nigerrimum (dashed lines/triangles). (b) Toxic dose, which was the mean number \pm SE of ants (and the equivalent amount in mg \pm SE of iridomyrmecin) per $g$ of juvenile amphibian that elicited an effect. SE are only shown when meaningful. Equivalent amounts of iridomyrmecin were calculated using the species-specific contents: 6.416 $\pm 0.443 \mathrm{mg}$ for $L$. humile and $1.291 \pm 1.127 \mathrm{mg}$ for $T$. cf. nigerrimum. 

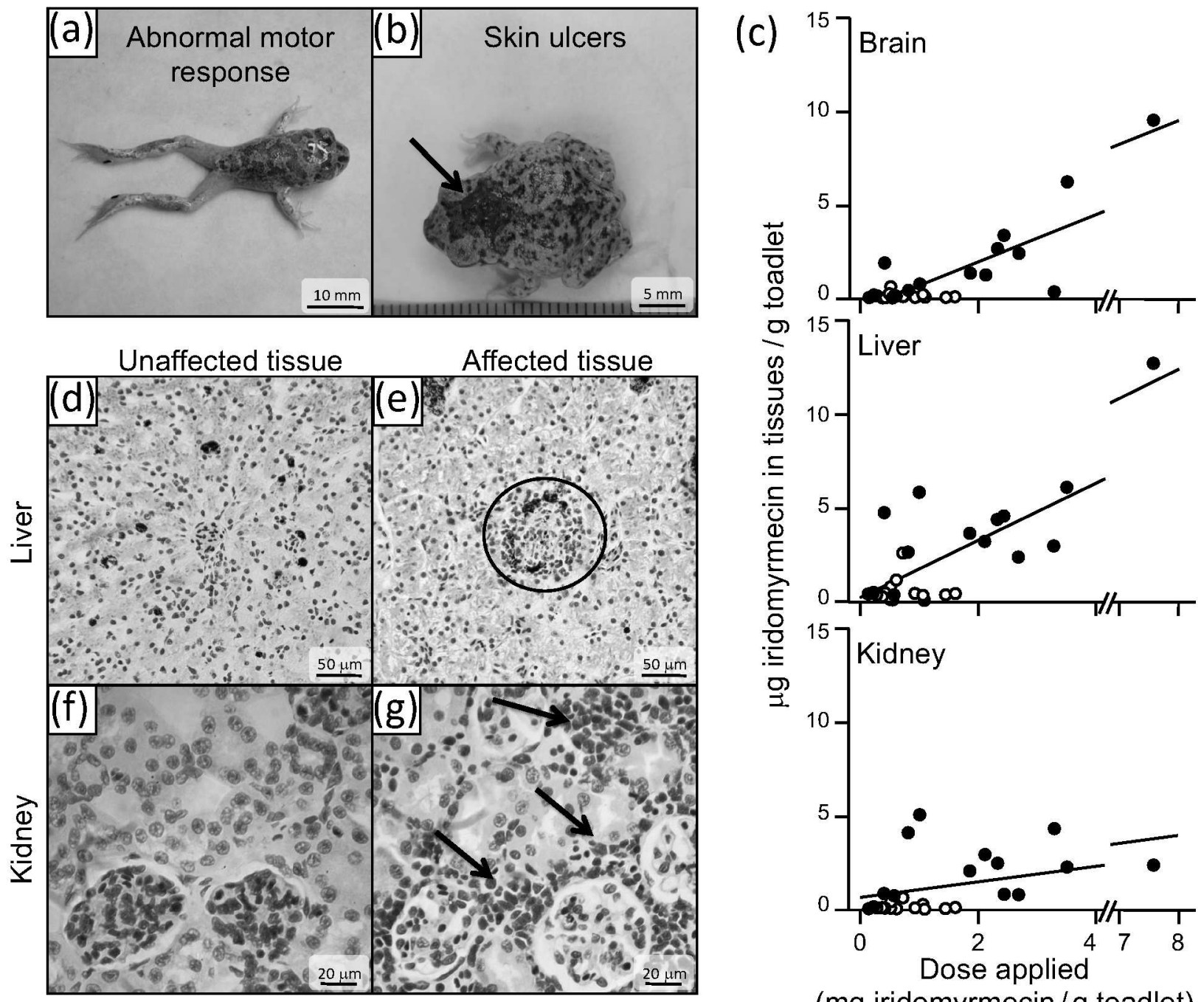

(mg iridomyrmecin/g toadlet)

Figure 3. Effects of iridomyrmecin on toadlets and toadlet tissues. Pelobates cultripes toadlet with (a) an abnormal motor response (ataxia, paresis, and flaccidity) and (b) with skin ulcers (marked with an arrow). (c) Relationship between the dose applied (equivalent amounts of iridomyrmecin estimated from the number of Linepithema humile [in black] or Tapinoma cf. nigerrimum [in white] applied to toadlets) and the concentration of iridomyrmecin measured in toadlet tissues after treatment. Model fit was determined using the combined data for all the amphibian species and ant species. (d) Unaffected liver. (e) Damaged liver with lymphoplasmocytic inflammatory infiltrates in the periportal space (circled). (f) Unaffected kidney. (g) Damaged kidney with acute tubulo-interstitial nephritis (marked with arrows). 


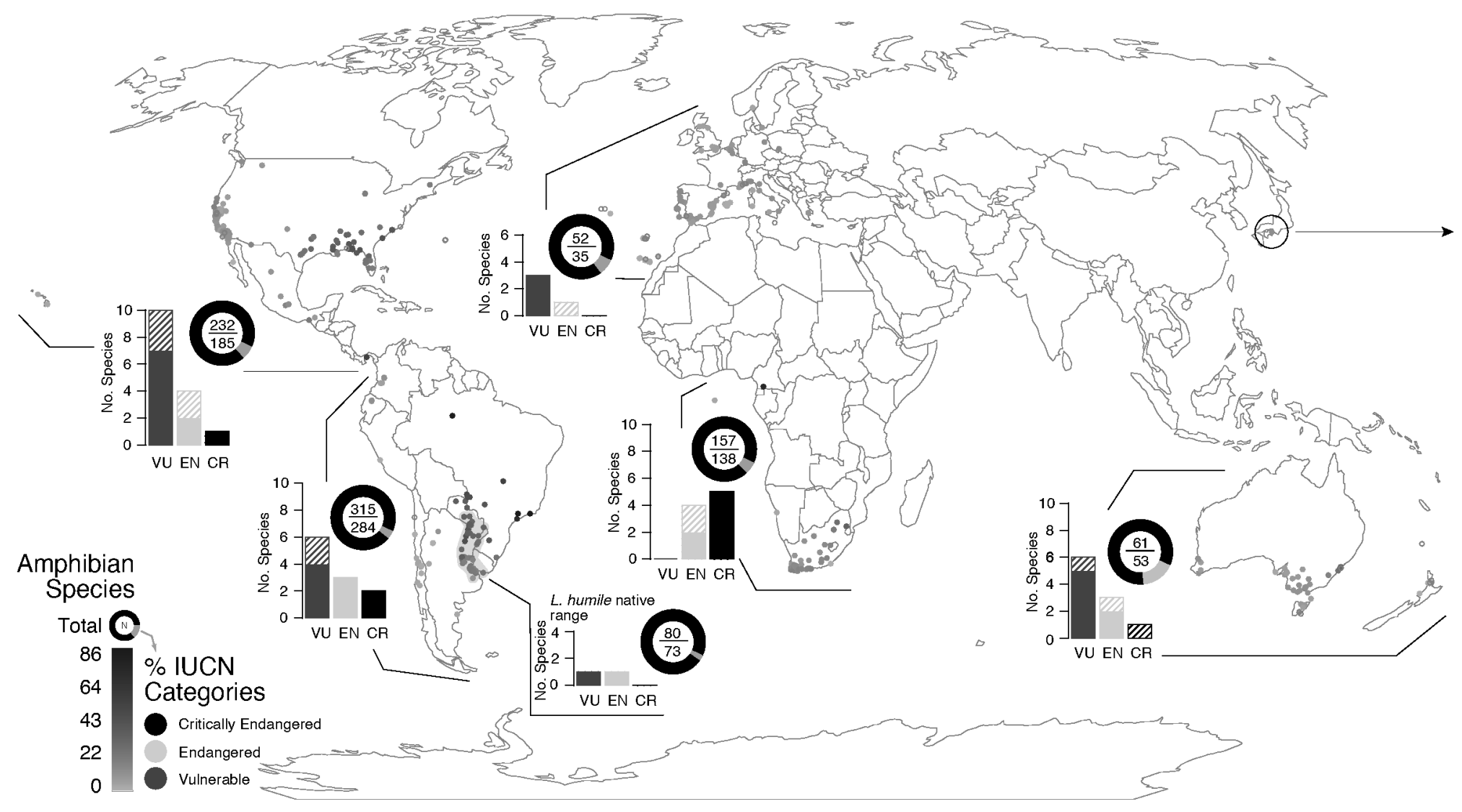


Figure 4. World map showing records of native and invasive $L$. humile populations. Point color reflects the number of co-occurring amphibian species (1:white to 86:black; 0:hollow, gray outline only) based on spatial and macrohabitat overlap, and the pie charts show regional species richness (range of cumulative number of species for the full dataset [top] and for the microhabitat-filtered dataset [bottom]) and the proportion of species in nonthreatened (black) and threatened (gray) IUCN Red List categories (for full dataset). The following regions were defined: the native range of $L$. humile, the rest of South America, North America (plus Japan), Europe (including European island colonies in North Africa), Sub-Saharan Africa, and Oceania. The bar charts for each region show the number of species that are vulnerable (VU), endangered (EN), and critically endangered (CR) for both the full (hashed) and microhabitat-filtered (filled) datasets. 